\title{
Proposed Technique for Optimally Sizing a PV/Diesel Hybrid System
}

\author{
Abd El-Shafy A. Nafeh \\ Electronics Research Institute \\ Cairo, Egypt \\ E-mail: abdelshafyn@eri.sci.eg, abdelshafyn@yahoo.com
}

\begin{abstract}
The combination of the remote-area-diesel generators with a battery storage and renewable energy source such as photovoltaic $(\mathrm{PV})$ can greatly overcome the problems of these generators. In this paper a PV/Diesel generator hybrid energy system is sized to meet the load for about $100 \%$ availability. Where, for a given load characteristic and a given diesel generator a methodology is developed to optimize the operation of the diesel generator and to calculate the optimum number of the PV modules and batteries that would achieve a minimum initial cost and a desired depth of discharge for battery storage, as indicated by the results.
\end{abstract}

\section{Key words}

Hybrid energy system, diesel generator, PV modules, storage battery, optimal sizing.

\section{Introduction}

The rapid depletion of fossil-fuel resources on a worldwide basis has necessitated an urgent search for alternative energy sources. Of the many alternatives, photovoltaic (PV) has been considered as promising toward meeting the continually increasing demand for energy. The PV source of energy is inexhaustible, free from pollution fumes, and has no moving parts. For remote systems such as radio telecommunications, satellite earth stations, or at sites that are far away from a conventional power system, the hybrid systems have been considered as attractive and preferred alternative sources [1-6].

Currently, most of remote areas in Egypt are electrified using stand-alone diesel generators, since they provide close to grid equivalent power supplies $[7,8]$. In rural electrification, the major problem faced by power generation using diesel generators is the sever fluctuation in load demand; whereas the diesel generator must be sized to meet the predicated peak loads even though this high load only need to be met for a small percentage of its operating time. Also, diesel generators operate most efficiently when running between $80-90 \%$ of their rated capacity and become less and less efficient as the load decreases. Therefore, stand-alone diesel generators sized to meet peak load will often be running inefficiently for a large portion of their operating time. In addition to poor fuel efficiency when running at low loads, the wear and corresponding maintenance requirements of diesel generators also increase as the load decreases. This effect can easily double the maintenance requirements of diesel generators and can halve their operating life [4,9]. Moreover, the diesel generator is considered as a poor reliability supply. Most of the drawbacks of using the stand-alone diesel generator can be overcome by combining the diesel generator with a battery storage and renewable energy source such as photovoltaic. This hybrid system combines the low initial cost of a diesel generator with a high initial cost of a PV array $[1,2,4,5]$.

In this paper a methodology is developed to optimize the sizing process of a PV/Diesel generator hybrid energy system.

\section{Hybrid Systems}

In some applications, it is both economical and desirable to use a hybrid system, whereby the PV supplies some or most of the load, but with an auxiliary generator as a backup. This allows the stand-alone PV system to be designed to a quite low availability, usually resulting in considerable savings on battery capacity and to a lesser extent on PV array.

The most common configuration of hybrid systems (Fig. 1) that are currently being installed is a PV/Battery standalone system, with a diesel generator as a backup for emergency use or for peak loads. Such systems are commonly used where availabilities near $100 \%$ are required, which would be prohibitively expensive using $\mathrm{PV}$ alone, and in residential or commercial applications where diesel generators previously dominated and were therefore already available.

Despite the high initial costs, where diesels are currently used, the addition of PV modules, batteries, and controller can greatly improve the efficiency of generator usage as well as substantially reducing system operating costs. Conversely, a diesel generator removes the need for oversized PV arrays, which would be both costly and poorly utilized [10]. 


\section{PV/Battery/Diesel Hybrid System Sizing}

To size any PV hybrid system, it is essential to have accurate information about the load to be supplied and the best available radiation data for the intended site [11].

\section{A. Determination of the Load Demand}

A typical daily load of a three isolated houses near Mersa Matruh city of Egypt is used, where this site has latitude of $31.33^{\circ}$ north. The load specifications data (Table I) are utilized to determine the load power demand on a typical day as shown in Fig. 2.

\section{B. Sizing of the Diesel Generator}

Diesel generator system design simply involves selecting a locally available unit that is closest to the peak load requirements of the application. Where, the diesel generator operates most efficiently when running between $80-90 \%$ of its rated capacity and become less and less efficient as the load decreases. Figure 2 indicates that the peak load lies between 11 am and $1 \mathrm{pm}$, then the diesel generator should be used in this period. The available diesel generator is $3 \mathrm{~kW}$ KUBOTA type [4], which can be started manually or automatically. Also, it is provided with a governor to provide the engine with the suitable quantity of fuel according to the corresponding load demand. The governor helps to keep the generator speed and consequently the generator frequency constant at any operating conditions. Therefore, to optimize the diesel generator operation during the selected period, it is selected to be loaded, in this case, with $85 \%$ of its rated power. Hence, the diesel generator must share the peak load with $2550 \mathrm{~W}$. Therefore, the daily energy required from the stand-alone PV system only, as indicated from Fig. 2, is $E_{L}=9126$ Wh.

\section{Determination of the Array Inclination and Orientation}

In a previous paper [12] the author developed a new technique to set the optimum array tilt to be the angle which maximizes the incident solar radiation on the PV array at solar noon. In this case, the array inclination is set to be $48^{\circ}$ from horizontal and facing the south direction, to maximize the incident global radiation on the array during the worst month (here, Dec.).

\section{Determination of the Incident Energy}

The radiation data for the studied site are available in the following reference [13]. These data and the PV array inclination angle are utilized to determine the incident solar radiation on the PV array, for a typical day in every month of the year, to be as shown in Table II.

\section{E. Determination of the Series-Connected Modules}

The number of modules $\mathrm{N}_{\mathrm{s}}$, which are to be connected in series string, is directly determined by the DC operating bus bar voltage (here, $\mathrm{V}_{\mathrm{DC}}=24 \mathrm{~V}$ ) and the peak-power voltage of the available module $\mathrm{V}_{\mathrm{mp}}(\approx 8.8 \mathrm{~V}$ for the considered site), as:

$$
N_{s}=\frac{V_{D C}}{V_{m p}}
$$

Always, the value of $\mathrm{N}_{\mathrm{s}}$, resulted from Eq. (1), is rounded to the next higher integer [14], thus $\mathrm{N}_{\mathrm{s}} \approx 3$.

\section{F. Determination of the parallel Strings}

The number of parallel strings of the PV modules $\mathrm{N}_{\mathrm{p}}$ can be deduced by writing down the energy balance equation for a typical day. The daily generated energy from the PV array, at the site insolation and temperature, can be written down in terms of the array peak-power voltage $\left(\mathrm{N}_{\mathrm{s}} . \mathrm{V}_{\mathrm{mp}}\right)$ and current $\left(\mathrm{N}_{\mathrm{p}} . \mathrm{I}_{\mathrm{mp}}\right)$ if the average daily sunshine period (SSP) of the site is known. Here, the SSP of the considered site is $9.30 \mathrm{~h}[13]$ and $\mathrm{I}_{\mathrm{mp}} \approx 1.466 \mathrm{~A}$. But, since the charging and discharging process of a battery results in some energy losses and since the longterm dust accumulation obstacles some part of sun light from passage to the array. Thus, by considering the overall efficiency of charging and discharging the battery $\eta_{B}$ ( $\approx 90 \%$ for lead-acid battery [14]) and taking into account the effect of dust accumulation factor DAF which allowing a further degradation in performance by about $10 \%$ [11]. Therefore, the daily available energy from the $\mathrm{PV}$ array $\mathrm{E}_{\mathrm{PV}}$ will be:

$$
E_{P V}=N_{p} I_{m p} \times N_{S} V_{m p} \times S S P \times \eta_{B} \times D A F
$$

The energy balance for a typical day can then yields:

$$
N_{p}=\frac{E_{L}}{I_{m p} \times N_{s} V_{m p} \times S S P \times \eta_{B} \times D A F}
$$

where, $\mathrm{E}_{\mathrm{L}}$ is the daily load demand from the stand-alone PV system only. The value of $\mathrm{N}_{\mathrm{p}}$, resulted from Eq. (3), is rounded up or down as deemed appropriate [14], thus $\mathrm{N}_{\mathrm{p}}$ becomes 31 .

\section{G. Sizing of the Storage Subsystem}

Batteries in PV systems operate under specific conditions which must be allowed for in the system design, as they affect both battery life and the efficiency of the battery operation. The most prominent feature is cycling with various cycles of different degree of regularity. During the daily cycle, the battery is charged during the day and discharged by the night-time load. Also, superimposed on the daily cycle is the climatic or seasonal cycle, due to the variable climatic conditions.

Since, the energy deficit will occur anytime when the load exceeds the energy supply from the array, thus the daily and seasonal energy deficits can now be calculated. It must ensure, here, that the night periods or shadows 
must be covered satisfactorily. At the same time, excess energy generated and not used during the sunshine periods must be stored. This analysis determines the charge/discharge percentage of the battery that usually can not exceed a given value for safe operation.

1) Calculation of the seasonal energy deficit The energy balance for the year is set in such a way that the seasonal energy excess (during summer) can be stored effectively to cover the cumulative energy deficit during the worst season (usually winter). Thus, it is easy to calculate the seasonal energy deficit $\Delta E_{s}$, using the MATLABSIMULINK block diagram of Fig. 3, as the monthly energy deficit between the PV array and the load. Figure 4 shows the monthly available energy from the PV array with respect to the load demand, where the value of $\Delta E_{S}$ is represented by the shaded area (i.e., $\Delta E_{s}=331087.33 W h$ ). It is to be noted that this energy deficit depends on the choice of the array size Ns $\times \mathrm{Np}$ and on the site-daily average sunshine period of each month.

2) Calculation of the daily energy deficit Because of system maintenance, failure, or lack of sunshine which is due to unpredictable cloud cover, it is necessary to have a further stored energy to cover the daily energy deficit not only for hours of night-time operation, but also for those days when the sun either does not shine at all or when it shines too little. The value of the daily energy deficit $\Delta E_{d}$, which depends only on the particular site of the system, is given by $[11,14]$ :

$$
\Delta E_{d}=E_{L} \times D
$$

where, $\mathrm{E}_{\mathrm{L}}$ is, as before, the daily load demand, and $\mathrm{D}$ is the number of storage days (i.e., days of autonomy). The number of autonomy days required for critical $D_{\text {crit }}$ and non-critical $D_{\text {non }}$ applications are determined, respectively, from the following two equations [14]:

$$
\begin{aligned}
& D_{\text {crit }}=-1.9 P S H_{\text {min }}+18.3 \\
& \text { and } \\
& D_{\text {non }}=-0.48 P S H_{\text {min }}+4.58
\end{aligned}
$$

where, $\mathrm{PSH}_{\text {min }}$ is the minimum peak solar hours for the selected site and array tilt during any month of operation. Note that the PSH is the number of hours of the standard insolation (1000 $\mathrm{W} / \mathrm{m}^{2}$ ) which would produce the same radiation. Clearly, PSH is numerically equal to the radiation in $\mathrm{kWh} / \mathrm{m}^{2} /$ day. As the worst month is, here, Dec., then $\mathrm{PSH}_{\min }$ is $3.90 \mathrm{~h}$ (Table II). Note, also, that the above two formulae are only valid for $\mathrm{PSH}_{\text {min }}$ $>1 \mathrm{~h}$. Either of these two equations can be used in PV system design depending on the required figure of availability. The system availability, in general, is defined as the percentage of time that a power system is capable of meeting the load requirements [10]. For instance, a system designed for $95 \%$ availability is expected to meet the requirements of the load $95 \%$ of the time. Therefore, higher availability figure is very important from the consumer's point of view. But, in actual system design the requirements of each specific application, solar radiation data at the site and the limit of the capital cost will determine the appropriate availability figure to aim for. Also, practically no stand-alone system can be designed to provide $100 \%$ availability at any cost, since there will be a sharp increase in the system cost as the availability of the system approaches $100 \%$ [10]. Since, the lack sunshine, system maintenance, and failures are the primary contributors to lowering PV system availability. Then, in stand-alone PV systems, availability will depend primarily on battery size. Hence, to reduce the overall system cost non-critical stand-alone systems are designed with an availability of about 95\% (Eq. (6)), whereas critical stand-alone systems are likely to require $99 \%$ availability (Eq. (5)). Moreover, it is both desirable and acceptable to design the hybrid and grid-connected systems with an availability of about $95 \%$ (Eq. (6)) to make considerable saving on battery capacity and to a lesser extent on PV size [10]. Therefore, the number of storage days, in this case, can be calculated from Eq. (6), to be $\mathrm{D}=\mathrm{D}_{\text {non }}=2.708$ days. Consequently, the corresponding value of the daily energy deficit can be obtained using Eq. (4), to become $\Delta \mathrm{E}_{\mathrm{d}}=24713.208 \mathrm{Wh}$.

3) Determination of the battery capacity Batteries are, primarily, used in PV systems to store the excess energy generated and not used during the sunshine periods, and to supply the load with the required energy in cases of deficit. Therefore, the battery size must be capable to supply the load with both the daily and seasonal energy deficits. But, to size the battery accurately, it is necessary to take into account the loss of capacity under conditions of low temperature, and the loss of energy due to the charging and discharging processes. Battery nominal capacity $\mathrm{Cn}$ is thus determined from:

$$
C_{n}=\frac{\Delta E_{s}+\Delta E_{d}}{V_{D C} T D F \eta_{B} D O D}
$$

where, the indicated symbols is as before, TDF is the temperature derating factor, and DOD is the selected maximum permissible depth of discharge of the battery. Shallow cycling batteries should not be discharged more than $25 \%$ of rated capacity, whereas deep cycling batteries can be discharged up to $80 \%$ [10]. In this work, the value of the DOD is selected to be $80 \%$. At the same time, since the lead-acid battery capacity decreases by about $1 \%$ per ${ }^{\circ} \mathrm{C}$ below about $20{ }^{\circ} \mathrm{C}$ 
$[10,11]$, then the approximate value of the TDF is given by:

$T D F=\frac{C_{T}}{C_{n}}= \begin{cases}1 & , T \geq 20{ }^{\circ} C \\ 1-0.01(20-T) & , T<20{ }^{\circ} C\end{cases}$

where, $\mathrm{C}_{\mathrm{T}}$ is the battery capacity at any temperature T. Since, the selected site has an annual average value for the ambient temperature of $19.35{ }^{\circ} \mathrm{C}$ [13], then Eq. (8) gives the approximate value of the TDF to be 0.99 . Therefore, Eq. (7) yields $C_{n}=20798.3$ Ah.

4) Determination of the battery configuration Once the nominal capacity of the battery bank is determined, the total number of batteries NB in the system can be determined from:

$N_{B}=\frac{C_{n}}{C_{B}}$

where, $C_{B}$ is the nominal capacity of a single battery. Normally, this computation will result in a non-integer quantity. The system designer must then decide carefully whether to round up or to round down to satisfy the requirements of the battery-bank configuration. Therefore, the number of batteries to be connected in series $\mathrm{N}_{\mathrm{Bs}}$ and that of parallel strings $\mathrm{N}_{\mathrm{Bp}}$ are calculated, respectively, using:

$$
N_{B s}=\frac{V_{D C}}{V_{B}}
$$

and

$$
N_{B p}=\frac{N_{B}}{N_{B s}}
$$

where, $V_{B}$ is the nominal voltage of a single battery. It is to be noted, here, that the nominal voltage and the nominal capacity of the used single battery are $12 \mathrm{~V}$ and $100 \mathrm{Ah}$, respectively, whereas the system voltage and the nominal capacity of the required battery bank are $24 \mathrm{~V}$ and 20798.3 Ah, respectively. Therefore, Eqs. (9), (10), and (11) can give $\mathrm{N}_{\mathrm{B}} \approx 208, \mathrm{~N}_{\mathrm{Bs}}=2$, and $\mathrm{N}_{\mathrm{Bp}}$ $=104$.

\section{H. Evaluation of the Most Economic Combination of Batteries and PV modules}

It is necessary to determine the most economic number of the PV/Battery combination that yields a minimum cost of the system. The cost function of the system can be defined as follows [3]:

$$
C=\alpha \cdot N_{s} \cdot N_{p}+\beta \cdot N_{B s} \cdot N_{B p}+C_{o}
$$

where:

C capital cost of the hybrid system,

$\alpha \quad$ cost of a single PV module,

$\beta \quad$ cost of a single battery,

$\mathrm{C}_{\mathrm{o}}$ the total constant costs including the cost of design, installation, and the diesel generator.

The condition to obtain the minimum cost for Eq. (12) is to put either $\frac{\partial C}{\partial N_{P V}}=0$ or $\frac{\partial C}{\partial N_{B}}=0$. Since, $\mathrm{N}_{\mathrm{PV}}=$ $\mathrm{N}_{\mathrm{s}} \cdot \mathrm{N}_{\mathrm{p}}$ and $\mathrm{N}_{\mathrm{B}}=\mathrm{N}_{\mathrm{Bs}} \cdot \mathrm{N}_{\mathrm{Bp}}$. Also, as in this work the values of $\mathrm{N}_{\mathrm{s}}$ and $\mathrm{N}_{\mathrm{Bs}}$ are restricted by the system voltage $\mathrm{V}_{\mathrm{DC}}$ (i.e., $24 \mathrm{~V}$ ) and the peak-power voltage of the PV module $\mathrm{V}_{\mathrm{mp}}$ (Eq. (1)) and the battery nominal voltage $\mathrm{V}_{\mathrm{B}}$ (Eq. (10)), respectively. Therefore, the values of $\mathrm{N}_{\mathrm{s}}$ and $\mathrm{N}_{\mathrm{Bs}}$ must be fixed, in this work, at 3 and 2, respectively, and the only variables in Eq. (12) will be $\mathrm{N}_{\mathrm{p}}$ and $\mathrm{N}_{\mathrm{Bp}}$. Thus, the condition to obtain the minimum cost is to put either

$$
\begin{aligned}
& \frac{\partial C}{\partial N_{p}}=0 \text { or } \frac{\partial C}{\partial N_{B p}}=0 . \text { Note that the condition } \\
& \frac{\partial C}{\partial N_{B p}}=0 \text { is chosen, in this work, which yields: }
\end{aligned}
$$

$$
\frac{\partial N_{p}}{\partial N_{B p}}=-\frac{\beta \cdot N_{B s}}{\alpha \cdot N_{s}}
$$

Therefore, for the designed availability figure of the stand-alone PV system (i.e., 95\%), the most economic combination of the number of the PV modules and batteries can be determined from a point on $\mathrm{N}_{\mathrm{p}}-\mathrm{N}_{\mathrm{Bp}}$ curve at which the slope of the tangent line to the curve is $-\left(\beta \cdot N_{B s}\right) /\left(\alpha \cdot N_{s}\right)$. Hence, for the designed availability figure of the stand-alone PV system, it is possible to calculate a series of possible combinations for the number of parallel strings of both the PV modules and batteries. These combinations are plotted as shown in Fig. 5. For a given price of batteries of $\$ 0.1$ per Ah and of PV modules of $\$ 2$ per $\mathrm{W}_{\mathrm{P}}$, a solution that minimizes the cost of the system can be found by drawing on the same plot a tangent line of slope $-\left(\beta \cdot N_{B S}\right) /\left(\alpha \cdot N_{s}\right)$. Therefore, the most economic values of $\mathrm{N}_{\mathrm{p}}$ and $\mathrm{N}_{\mathrm{Bp}}$ are 37 and 31 strings, respectively, as shown in Fig. 5.

\section{Check on the Battery State of Charge}

Finally, the proposed sizing technique must ensure the optimum and safe operation for both the selected sizes of the diesel generator and the battery bank. Since, the diesel generator, in this work, starts up to cover $85 \%$ of the peak load (i.e., the operating time of the diesel generator is from 11 am to $1 \mathrm{pm}$ ), therefore the operation of the diesel generator can be optimized, in this work, through increasing its fuel efficiency during its operating time. Whereas, in this work, the used battery bank is 
charged any time whenever there is an excess energy from the PV array and discharged during periods of deficit (i.e., during little sunshine hours or during night hours). And, since, it is known that the battery life is enhanced as long as its state of charge (SOC) remains near $100 \%$ or returns to that state as quickly as possible after a partial or deep discharge condition. Thus, in this work, to optimize the operation of the used battery bank, it is better to have lower values of the battery depth of discharge all over the year. Also, to guarantee the safe operation of the used battery size, the charging and discharging processes of the used battery bank have to be restricted within the designed allowable values of the maximum and minimum state of charges, respectively. Therefore, for the most economic number of batteries and PV modules, the SOC of the battery bank throughout the year must be checked. The MATLAB-SIMULINK block diagram of Fig. 6 was designed for this purpose. Figure 7 shows the SOC of the battery bank throughout the year for the resulted economic combination of batteries and PV modules. Thus, it is seen, from this figure, that during some winter months (i.e., Jan., and Dec.), the battery bank seems to be more deeply discharged than other months of the year; and this is due to the corresponding lower generated power from the PV array (which depends, mainly, upon the incident solar radiation on the PV array) during these months. Consequently, the solar radiation data of Table II illustrates that the considered battery size will be in discharging condition most of the time during these two months, and the worst month of the year is, here, December. Thus, Fig. 7 indicates that not only the economic combination will be the most economic one, but also will prolong the life of the batteries due to the corresponding acceptable maximum depth of discharge at the worst month $(\approx 40 \%)$ that not exceed the designed permissible maximum limit of $80 \%$. Therefore, the most economic combination is considered, here, to be the optimum one.

\section{Conclusions}

Most of the drawbacks of using the diesel generator alone can be overcome by using a PV/Diesel generator hybrid system. The considered hybrid system is sized to meet the load of a three houses for about $100 \%$ availability. Where, for the given load characteristic and diesel generator a methodology, which uses the site-climatic conditions, is developed to calculate the optimum mix of the system components. The diesel generator is optimally sized to meet the peak load with $85 \%$ of its rated power. Whereas, the PV array is adjusted to face the south direction with an angle from horizontal that maximizes the incident solar radiation on the array during the worst month. The effect of the site annual average insolation and temperature values are reflected on the sizing process of both the PV modules and batteries. The sizing of the PV modules is based on the module characteristic, system voltage, and the daily energy balance between the PV array and the load. At the same time, the battery is sized such that it must be capable to supply the load with both the daily and seasonal energy deficits. Whereas, the optimum mix of the PV modules and batteries is determined based on the minimum cost of the system and the desired depth of discharge of the battery bank.

\section{References}

[1] A. Al-Alawi, S.M. Al-Alawi, and S.M. Islam, "Predictive Control of an Integrated PV-Diesel Water and Power Supply System Using an Artificial Neural Network", Renewable Energy, Vol. 32, pp. 1426-1439, 2007.

[2] S. Ashok, "Optimized Model for Community-Based Hybrid Energy System", Renewable Energy, Vol. 32, pp. 1155-116, 2007.

[3] B.S. Borowy and Z.M. Salameh, "Methodology for Optimally Sizing the Combination of a Battery Bank and PV Array in a Wind/PV Hybrid System", IEEE Trans. on Energy Conversion, Vol. 11, No. 2, pp. 367-375, 1996.

[4] S.H. El-Hefnawi, "Photovoltaic Diesel-Generator Hybrid Power System Sizing”, Renewable Energy, Vol. 13, No. 1, pp. 33-40, 1998.

[5] S.M. Shaahid and M.A. Elhadidy, "Economic Analysis of Hybrid Photovoltaic-Diesel-Battery Power Systems for Residential Loads in Hot Regions-A Step to Clean Future", Renewable and Sustainable Energy Reviews, Vol.12, pp. 488-503, 2008.

[6] W.X. Shen, "Optimally Sizing of Solar Array and Battery in a Standalone Photovoltaic System in Malaysia", Renewable Energy, Vol. 34, pp. 348-352, 2009.

[7] S. Kamel and C. Dahl, "The Economics of Hybrid Power Systems for Sustainable Desert Agriculture in Egypt", Energy, Vol. 30, pp. 1271-1281, 2005.

[8] R. Taylor and F. Abulfotuh, Photovoltaic Electricity in Egypt, Project Brief: http://www.rsvp.nrel.gov, 2005.

[9] S. Trihadi, "Eastern Indonesia Hybrid Energy Project: Design and Implementation", Proc. of 12th International Photovoltaic Science and Engineering Conference (PVSEC-12), June 11-15, Jeju, Korea. pp 331-333, 2001.

[10] S.R. Wenham, M.A. Green, and M.E. Watt, Applied Photovoltaics, Center for Photovoltaic Devices and Systems, Australia, 1994

[11] M.A. Green, Solar Cells, Operating Principles, Technology, and System Applications, N. J.: PrenticeHall Inc., Englewood Cliffs, 1982.

[12] A.A. Nafeh, "Evaluation of the Optimum Tilt of a PV Array Using Maximum Global Insolation Technique", Int'l Journal of Numerical Modelling: Electronic Networks, Devices and Fields, Vol. 17, No. 4, pp. 385395, 2004.

[13] Egyptian Solar Radiation Atlas, New and Renewable Energy Authority, Ministry of Electricity and Energy, Cairo, Egypt, 1998.

[14] R. Messenger and J. Ventre, Photovoltaic Systems Engineering, CRC Press LLC, Boca Raton, FL, USA, 2000. 


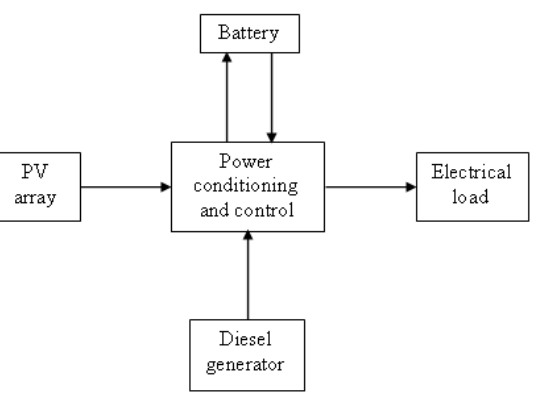

Fig. 1 PV/Diesel generator hybrid system.

Table I. - Load data of the three houses

\begin{tabular}{|c|c|c|c|c|}
\hline Appliance & $\begin{array}{c}\text { No. of } \\
\text { appliances }\end{array}$ & $\begin{array}{l}\text { Duty } \\
\text { cycle }\end{array}$ & $\begin{array}{l}\text { Used period } \\
\text { (hi) }\end{array}$ & $\begin{array}{c}\text { Total } \\
\text { power (W) }\end{array}$ \\
\hline Liring lamp 40777 & $5 \times 3$ & 0.6 & $18-24$ & 360 \\
\hline Bedroom lamp $15 \mathrm{~W}$ & $2 \times 3$ & 0.5 & $24-6$ & 45 \\
\hline Desklamp $30 \mathrm{WW}$ & $1 \times 3$ & 0.6 & $18-24$ & 54 \\
\hline TV set $601 \mathrm{WT}$ & $1 \times 3$ & 0.5 & $10-15,18-24$ & 90 \\
\hline Radio cassette $15 \mathrm{~W}$ & $1 \times 3$ & 0.5 & $6-10$ & 22.5 \\
\hline T77 ashing machine $900 \mathrm{~W}$ & $1 \times 3$ & 0.6 & $11-13$ & 1620 \\
\hline Putmp 500 TT & $1 \times 3$ & 0.8 & $11-13$ & 1200 \\
\hline Refrigerator $110 \mathrm{~W}$ & $1 \times 3$ & 0.6 & 24 houlss & 198 \\
\hline
\end{tabular}

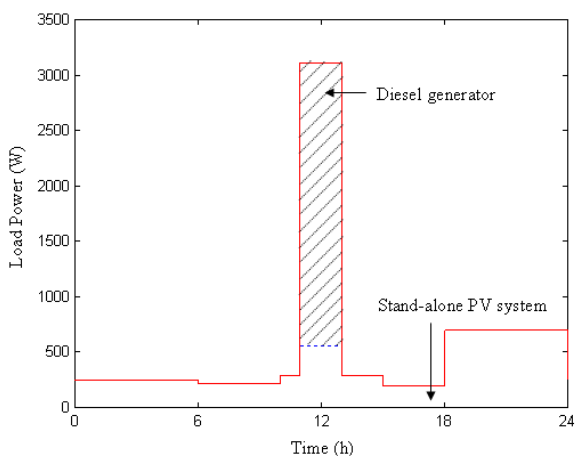

Fig. 2 Load profile.

Table II. - Average daily radiation data on the PV array (array inclination $48^{\circ}$ )

\begin{tabular}{|c|c|c|c|c|c|c|}
\hline Month & Jati & Febl & Mar' & Aptr & May & Juni \\
\hline Ifradiation (kTh/miday) & 4.018 & 4.73 & 562 & 6.21 & 6.36 & 6.60 \\
\hline Month & Jul & Aug & Sep & Oct & Norn & Dec \\
\hline Ifradiation (kTh/m2/day) & 6.71 & 673 & 6.53 & 5.55 & 4.63 & 3.90 \\
\hline Antulual meat & \multicolumn{6}{|c|}{$8.64 \mathrm{kTh}^{2} \mathrm{~mm} / \mathrm{dat}$} \\
\hline
\end{tabular}

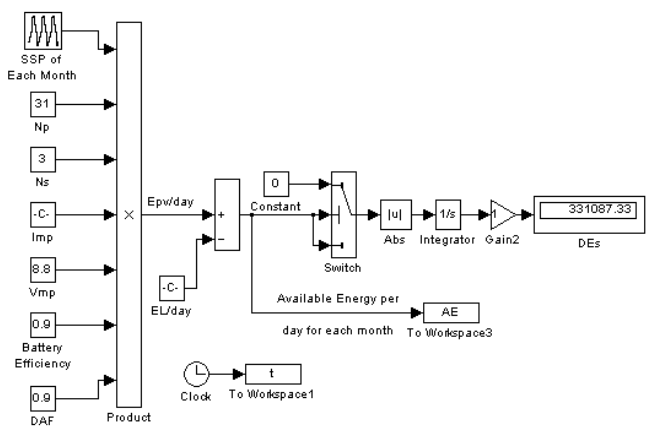

Fig. 3 SIMULINK block diagram to calculate $\Delta E_{s}$.

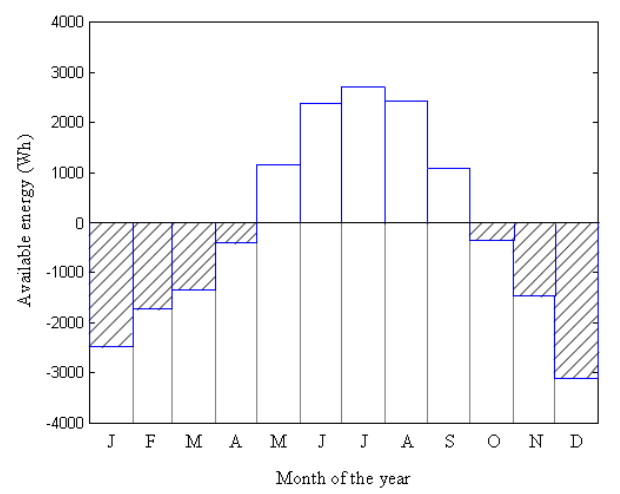

Fig. 4 Monthly energy balance between the PV array and the load.

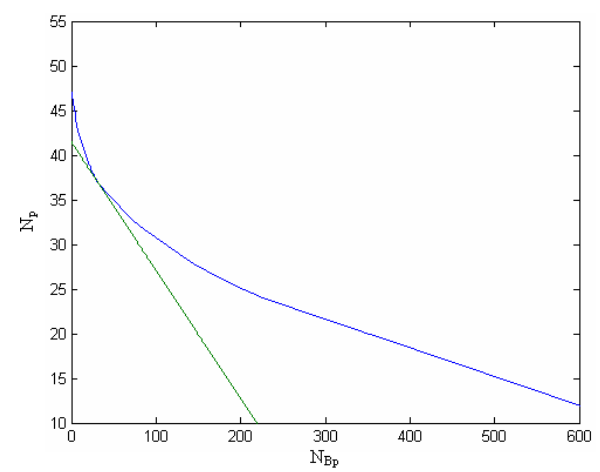

Fig. 5 Possible combinations of $\mathrm{N}_{\mathrm{p}}$ and $\mathrm{N}_{\mathrm{Bp}}$ for the same availability with the most economic solution.

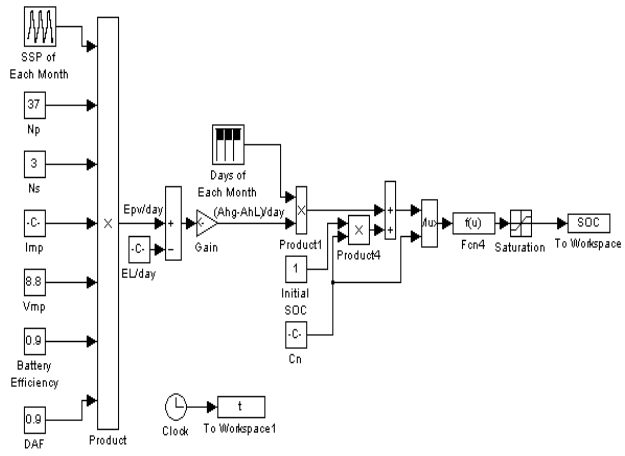

Fig. 6 SIMULINK block diagram to calculate the battery SOC.

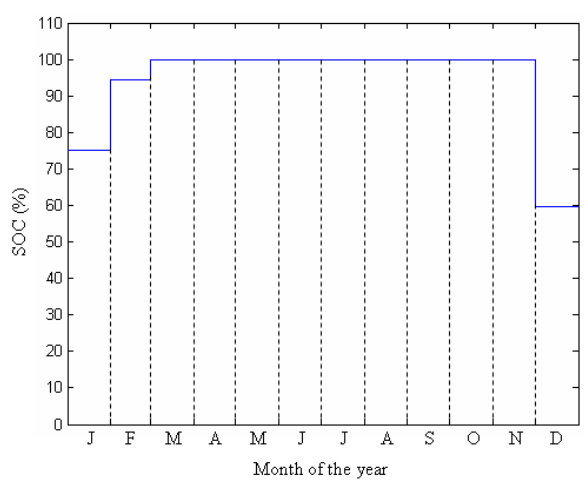

Fig. 7 State of charge of battery bank throughout the year. 